\title{
Influences of Flow Transients and Porous Medium Heterogeneity on Colloid-Associated Contaminant Transport in the Vadose Zone
}

\author{
James E. Saiers \\ School of Environmental Studies \\ Yale University \\ 21 Sachem Street \\ P.O. Box 208105 \\ New Haven, CT 06511
}

\section{RESEARCH GOALS}

We are investigating the role of colloids in the movement of radionuclides and metals through waterunsaturated porous media. This research is guided by a key objective of the Environmental Management Science Program (EMSP), which is to improve conceptual and predictive models for contaminant movement in complex vadose zone environments. In the report entitled National Roadmap for Vadose Zone Science and Technology [DOE, 2001], increases in the understanding of colloid-contaminant interactions, colloid mobilization, and colloid deposition within unsaturated soils are cited as requisite needs for predicting contaminant fate and distribution in the vadose zone. We seek to address these needs by pursuing three overarching goals: (1) identify the mechanisms that govern colloid mobilization, transport, and deposition within unsaturated porous media; (2) quantify the role of colloids in scavenging and facilitating the transport of contaminants; and (3) develop and test a mathematical model suitable for simulating the movement of colloid-associated radionuclides and metals through variably saturated porous media.

\section{RESEARCH PROGRESS}

This report summarizes work after fifteen months of a three-year project that began in September 2003. This is a collaborative effort between PIs at Yale University (Saiers) and the University of Colorado (Ryan). Funds from the awards support the research of a postdoctoral associate and two Ph.D. students. Our research plan calls for laboratory-scale experiments on colloid and radionuclide migration and on the development of mathematical models that are capable of describing the experimental observations. Considerable progress has been made on both the laboratory and theoretical components of the study. We have designed and constructed large columns appropriate for conducting experiments on the movement of inorganic colloids and colloid-associated radionuclides and metals through variably saturated geologic materials. These columns are instrumented with an array of probes for measuring and recording spatiotemporal variations in volumetric moisture content and capillary-pressure head. Experiments thus far have focused on (1) measuring colloid transport through both water-saturated and unsaturated columns packed homogeneously with quartz sand and (2) measuring colloid and associated metal mobilization from unsaturated natural sediments. The experiments examining colloid transport in quartz sand are being conducted under both steady- and transient-flow regimes and for porewater $\mathrm{pH}$ values ranging from 4 to 7.5. Illite clay and kaolinite clay serve as the colloidal particles in these experiments. The results of the experiments conducted under steady-flow conditions reveal that the deposition (immobilization) of both kaolinite and illite is sensitive to variation in volumetric moisture content and that deposition rates of kaolinite are more sensitive to changes in porewater $\mathrm{pH}$ than those of illite. In order to describe these data, we have developed a mathematical model that accounts for (1) advective-dispersive transport, (2) straining of porewater colloids within narrow porewater conduits that line partially saturated pores, (3) colloid capture at air-water interfaces, and (4) colloid attachment to the porous-medium mineral grains.

Comparison of model calculations to measurements made in the column experiments suggest that straining is the dominant colloid-immobilization mechanism for both illite and kaolinite at $\mathrm{pH}$ greater than or equal to 6. Below pH 6, straining persists as the dominant removal mechanism for illite, but mineral-grain attachment and air-water interface capture immobilize more kaolinite colloids than straining. We find that the release of deposited colloids is very slow or negligible under steady flow conditions, but that transients 
in porewater flow (that are typical of rainfall-induced infiltration events) promote rapid release of immobile colloids into the pore fluid. This mobilization occurs during both imbibition (wetting) and drying of the porous medium. During column imbibition, mobilization of kaolinite and illite is likely driven by shear stress imposed on the immobile colloids by the infiltrating water and by expansion of narrow porewaterflow conduits that strained colloids prior to imbibition. A different mechanism contributes to mobilization during porous-medium drainage. Our results provide strong evidence that moving air-water interfaces associated with downward-propagating drying fronts are capable of scavenging sand-bound colloids and facilitating their transport through the sand pack. The efficiency of these air-water interfaces in scouring immobile colloids varies in a discernible fashion with drying-front velocity and porewater chemistry. A model that approximates the sand pack as a bundle of capillary tubes and that links pressure-head changes during drainage to the rates of air-water interface movement through the tubes closely reproduces the data on colloid mobilization measured during column drainage. In the experiments on colloid and associated metal mobilization in natural sediments, we examined the effect of simulated rainfall rate on the spatial heterogeneity of the mobilization of colloids and colloid-bound metals. To understand a spectrum of behavior of metal adsorption to the colloids, which were composed of both clay minerals and organic matter, we focused our measurements on zinc, copper, and lead. The rainfall solution was $0.01 \mathrm{mM}$ sodium chloride solution at $\mathrm{pH}$ 5.7. Intact natural soil columns $(20 \mathrm{~cm}$ depth) were placed in the rainfall simulator and the column effluent was sampled in sixty-eight ports in the column base. The samples were collected at zero tension. The natural soil contained high concentrations of these metals, but two rainfall events of relatively high intensity mobilized only up to $8 \%$ of the metals in the soil. For the metal that was transported, the extent of colloid-facilitated transport increased in the order zinc $<$ copper $<$ lead. This order follows the strength of binding of these metals to clay minerals and organic matter. Other important properties of the soil and the porewater solution did not have a significant effect on the extent of colloidfacilitated transport, including $\mathrm{pH}$ (range 5.2 to 6.2) and the colloid size distribution (as measured by single-particle optical spectrometry). The amount of bound zinc and copper decreased slightly as the concentration of calcium in the porewater increased, but calcium did not have a significant effect on the bound lead concentration.

\section{PLANNED ACTIVITIES - NEXT SIX MONTHS}

Our results to date have succeeded in illuminating relationships between measurable system properties and colloid-transport characteristics. We will extend this work to examine how colloid transport influences the mobility of radionuclides within unsaturated porous media. The colloid effect on the migration of cesium and strontium will be measured first in columns packed homogeneously with sand and then in intact cores that we will collect from DOE sites. The column experiments will be carried out concomitantly with batch experiments designed to measure the kinetics of radionuclide adsorption to (and desorption from) the mineral colloids. In addition to column and batch experiments, the remainder of the second year will be devoted to the fabrication of micromodels. These transparent representations of a porous medium will permit testing of our hypotheses on the suite of mechanisms that govern colloid deposition and mobilization. This information on colloid-release and colloid-deposition mechanisms will be used in coordination with the batch and column data to parameterize and refine a mathematical model for colloidfacilitated radionuclide transport in partially saturated porous media. 